of aspirin described by Hanzlik and his colleagues in a series of papers published in $1917 .^{3}$

Paul Plotz ROBERT KIMBERLY JOHN R GILL JUN

National Institutes of Health, Bethesda,
Maryland

William Seaman

Veterans Administration Hospital, San Francisco,

California

${ }^{1}$ Seaman, W E, and Plotz, P H, Arthritis and Rheumat-

ism, 1976, 19, 155 .
Huskisson, E C, et al, British Medical fournal, 1974, $1,176$.

anzlik, P J, Scott, R W, and Thoburn, T W, Archives

of Internal Medicine, 1917, 19, 1029.

\section{Superficial carcinoma of the stomach}

SIR, - We have read with interest the article by Dr G Machado and others (10 July, p 77). Since the introduction of fibreoptic endoscopy at St Luke's Hospital, Malta, in October 1975 we have diagnosed two cases of superficial gastric carcinoma in a total of 120 patients subjected to gastroscopy. In both cases the endoscopic appearances were not impressive and in one case there was a long history of dyspepsia with negative barium studies. This has stimulated us to perform biopsy on any lesion or irregularity of gastric mucosa, no matter how insignificant the appearance, with a view to the early detection of gastric carcinoma.

FF FENECH A Caruana Galizia

Royal University of Malta, Medical School,

Guardamangia

Malta

\section{Aplastic anaemia and hair dye}

SIR,-One must take exception to $\mathrm{Dr} A \mathrm{~J}$ Jouhar's contention (1 May, p 1074) that the fatal case of aplastic anaemia described by Drs P J Toghill and R G Wilcox (28 February, p 502) "was probably if not definitely due to either oxytetracycline or penicillin and that it is doubtful that the hair dye in question was causal."

There appear to be no published case reports of aplastic anaemia unequivocally associated with penicillin, and the report cited by Dr Jouhar for oxytetracycline appears to be unique. Agreed, isolated cases have been privately communicated to drug safety committees, but the significance of these is often compromised by inadequate reporting and follow-up. Even so, the Panel on Hematology, Registry on Adverse Reactions of the Council on Drugs of the American Medical Association, between 1 July 1963 and 31 December 1966 tabulated only two cases with penicillin alone and one case each with penicillin and oxytetracycline combined with other presumably innocuous drugs.

On the other hand there are four apparently valid published cases and two Registry cases associated with hair dyes. In addition to the case reported by Drs Toghill and Wilcox and the one reported more recently by Drs $S$ Hamilton and J G Sheridan (3 April, p 834) there are two earlier cases published by Baldridge $^{1}$ and Thompson. ${ }^{2}$ In the first of these one of the hair dyes was specifically identified as para-phenylenediamine. In all four there was a definite temporal relationship between exposure and clinical symptoms. An additional two unpublished cases involving hair dyes, rinses, and tints were reported to the Panel on Hematology, Registry on Adverse Reactions of the Council on Drugs of the American Medical Association, between 1 July 1963 and 30 June 1964.

R J HANS

Medical Affairs Division,

Parke, Davis and Co,

Detroit, Michigan

Baldridge, C W, American fournal of the Medical Scicnces, 1935, 189, 759 .

2 Thompson, S J, Nursing Times, 1965, 61, 12.

\section{Compulsory seat belts}

SIR,-Dr W A Fraser-Moodie (17 July, p 178) expresses the hope that the public would respond to legislation to make them wear seat belts, but his own figures show that only half of those who have suffered injury from not wearing a belt are now regular wearers. So what hope has legislation? His cases, like those I see, were mostly cuts from windscreen glass, which presumably would not have happened if the windscreen had been laminated. The fitting of such windscreens can be effectively enforced by law, at least on all new cars, yet Britain still churns out cars with unlaminated ones. Even when specifically requested I was not given what I wished and I know of others who have had similar difficulties.

In Australia (Dr John Knight, 5 June, $\mathrm{p}$ 1391) it seems that injuries, although reduced by seat belts, still happen and laws restricting personal freedom are difficult to enforce. Without a breakdown of the figures to show whether more injuries are from lack of seat belts or lack of laminated windscreens and also what are attributable to the wearing of belts or to having laminated windscreens statistics are of little value. But a law that cannot be enforced and that the police do not like is a bad law and will continue to be flouted. One recent patient with a perforating eye injury with traumatic cataract from broken windscreen glass, when asked about seat belts, was quite adamant that she would continue to be a non-wearer.

I think one can expect the young especially to continue to drink, to drive, and to value their freedom rather than their safety in spite of any legislation.

\section{Regional Eye Centre,
Oldchurch Hospital,}

Oldchurch Hospital,
Romford, Essex

\section{Tuberculosis of the colon}

SIR,-Over the past few years there appears to have been an increase in the incidence of tuberculosis affecting the large bowel. This increase is not wholly confined to immigrant populations and consequently the diagnosis may not be initially considered. We have recently seen two patients, one thought to have a carcinoma and the other Crohn's disease, who illustrate different presentations of the disease.

Case 1-A 56-year-old Englishwoman who had never been abroad presented with a microcytic hypochromic anaemia. During investigation a barium enema examination revealed a stricture in the ascending colon suggestive of a carcinoma. At laparotomy a narrowed ring lesion was found in the distal right colon with nodes in the meso-colon. A right hemicolectomy was performed and she made an uneventful recovery. Histological examination showed a constricting lesion consisting of caseating giant-cell granulomas with mucosal ulceration. Acid-fast bacilli were present. There was no other evidence of tuberculosis either in the chest or urinary tract. She has been started on a course of antituberculosis treatment (isoniazid, rifampicin, and streptomycin) and is progressing well.

Case 2-A 43-year-old male Pakistani who had been resident in Britain for 18 years presented with typical small-bowel obstruction. At laparotomy a large hard mass was found in the caecum and an initial diagnosis of Crohn's disease was made. A right hemicolectomy was performed and he made an uneventful recovery. Histological examination showed mucosal ulceration and fissure formation in the caecum with caseous granulomas within the large bowel and lymph nodes. Acid- and alkali-fast bacilli were identified in the granulomas. There was no evidence of active tuberculosis elsewhere and he has been started on antituberculosis therapy.

In both these cases it is most probable that the lesions occured as a result of post-primary activation of previously acquired foci. Frequently one finds no evidence of tuberculosis elsewhere, either active or old, ${ }^{1}$ and this should not distract one from the diagnosis.

We feel bound to comment also on the very real increase in the incidence of Crohn's disease affecting the large bowel which has also occurred in recent years.

I TAYLOR

P BROOMAN

Royal Hospital,
Sheffield 1 Kaufman, H D, and Donovan, I, fournal of the Royal
College of Surgeons of Edinburgh, 1974, 19, 377.

\section{Sacrococcygeal teratoma and}

\section{"non-immunological" hydrops fetalis}

SIR,-Hydrops fetalis due to rhesus blood group incompatibility is becoming progressively less common and fetal hydrops from other causes (sometimes referred to as "nonimmunological" or "idiopathic") attracts increasing interest. A number of conditions associated with the latter have been reported with varying frequency; these include instances of anaemia due to haemoglobinopathy (Hb Barts), ${ }^{1}$ anaemia due to transplacental leakage (feto-fetal or feto-maternal ${ }^{2} 3$ ), congenital leukaemia, ${ }^{4}$ fetal heart disease (for example, endocardial fibroelastosis, ${ }^{5}$ premature closure of the ductus arteriosus, ${ }^{6}$ premature closure of the foramen ovale ${ }^{7}$ ), cystic malformation of the lungs," intrauterine infections, ${ }^{5}$ chromosomal aberrations, ${ }^{5}$ and, last but not least, haemangiomatous tumours of the placenta. ${ }^{8}$ This is by no means a complete list. Mechanisms by which one or the other of these associations can cause hydrops have been suggested, but clarification of many problems is still being awaited.

Recently I had the opportunity of observing a stillborn fetus which was undoubtedly hydropic, even though macerative changes were superimposed. The placenta too was hydropic and this was confirmed by histological examination. The common type of blood group incompatibilty was excluded by routine antenatal tests. Post-mortem examination did not suggest other forms of blood disorder; in particular, the liver and spleen were of appropriate size. A large sacrococcygeal teratoma measuring approximately $20 \mathrm{~cm}$ 